Article

\title{
Immersive Virtual Reality-Aided Conjoint Analysis of Urban Square Preference by Living Environment
}

\author{
Seungnam Kim ${ }^{1}{ }^{\mathbb{D}}$, Jaecheol Kim ${ }^{2, *}$ and Beakchan $\mathrm{Kim}^{1}$ \\ 1 Department of Urban Design and Studies, Chung-Ang University, Seoul 06974, Korea; \\ snkim@cau.ac.kr (S.K.); kk000127@naver.com (B.K.) \\ 2 Department of Urban Planning and Landscape Architecture, Gachon University, Seongnam-Si 13120, Korea \\ * Correspondence: jckim@gachon.ac.kr; Tel.: +82-31-750-5282
}

Received: 31 May 2020; Accepted: 4 August 2020; Published: 10 August 2020

check for

updates

\begin{abstract}
Though several studies have explored the ways in which people perceive the qualities of urban squares, the influence of living environments on such perceptions has received little attention. To fill this gap, this study examined differences in preferences for urban square design elements, particularly, the ratio of the width of a public space to the height of the surrounding buildings (D/H ratio), square size, and façade details, among people with different living environments. Virtual reality simulation techniques were used in controlled experiments with 100 participants of various nationalities, mostly Koreans, and conjoint analysis was applied to determine what combination of design elements most influenced urban square preferences. Participants experienced eight virtual squares designed with different combinations of the three design elements and assessed them based on five indicators of the quality of urban squares. Among the three design elements, the $\mathrm{D} / \mathrm{H}$ ratio most significantly influenced the perceptions of quality, regardless of participants' living environments. We conclude that the level of experience in various urban environments may affect people's familiarity with these environments and their spatial perception and preferences. We thus suggest that socio-cultural differences related to users' living environments should receive more attention in urban design practice. We also demonstrate that the emerging combination of immersive virtual reality technology and conjoint analysis can function as a useful tool for urban design research.
\end{abstract}

Keywords: virtual reality; urban squares; environmental perception; conjoint analysis

\section{Introduction}

Many scholars have considered urban squares to be one of the most important elements of a great city [1-5]; for example, Kevin Lynch noted the intense interest in squares (or plazas) in the urban design field [3]. In imaging the ideal urban square, we may generally recall stereotyped, human-scale European squares surrounded by beautiful buildings, filled with people drinking coffee and chatting in open-air cafes, people walking their dogs, people waiting for their friends, and lovers sitting side-by-side on the edge of a fountain. However, the form of European squares is not universal and is, rather, deeply rooted in the history and culture of Western society, although such daily human behaviors can be observed over the world. For example, streets have traditionally accommodated such social activities in Korea, while bazaars have served these functions in Islamic countries [6-8]. As noted by Lynch, the square model originates from historic European cities [3]. Beyond urban squares, many other design elements and principles of contemporary urban spaces, if not all, have their roots in Western, particularly European, society, and such design traditions have spread worldwide in recent decades as a feature of rapid globalization [9].

However, urban design ideas that have evolved in the urban environment of Europe have sometimes caused problems related to socio-cultural differences elsewhere in the world [10-13]. 
While urbanization has long occurred in European cities, inciting the natural integration of people's daily lives and urban spaces within these cities, many cities in other cultures have seen mismatches between these lives and spaces, which have been created by accepting European design principles with little criticism [10]. Since the living environment in which people grow up affects their preferences, people's preferred urban environments may vary according to their living environments, and such differences in living environments can exist even within the same country. For example, the lifestyles and living environments in rural areas may differ from those in urban areas [14]. To apply urban design principles to various places with different contexts, urban designers need to understand different spatial perceptions and the preferences of users for each place.

Against this backdrop, this study examines how people who have grown up in different living environments perceive the design elements of urban squares, which are representative open spaces in the West (particularly in Europe). For this, we conducted an immersive virtual reality (IVR)-aided conjoint experiment (visual assessment survey) involving 100 university students with different living environments. This approach allows people to "jointly" perceive and evaluate the elements of urban squares under controlled experiment conditions, thereby identifying which factors people most value.

\section{Literature Review}

\subsection{Evolution of European Urban Squares}

European urban squares accommodating social life and civic engagement, which are the research subject for this paper, are considered one of the most important elements in mainstream urban design field. For example, Kevin Lynch described the intense interest in squares (or plazas) in the urban design field, "Books on city design are full of its possibilities, at times it has almost appeared that urban design might simply be a matter of plaza design" [3] (p. 443).

Such European urban squares are unique inventions of European history and have been the core public spaces of most European cities for over two thousand years, functioning as social gathering places and markets [15-17]. Urban squares are rooted in the ancient Greek Agora and Roman Forum, and similar public spaces are found in almost all historic cities throughout Europe $[15,18]$. Although they have been variously named depending on time and place (e.g., agora, forum, piazza, or plaza), urban squares are distinguishing characteristics of historic European cities [15,17].

Particularly, traditional European urban squares are mostly surrounded by an almost continuous vertical wall of human-scale buildings with mixed uses [15]. These vertical elements formulate a visual enclosure within the squares, and the spaces have a room-like quality [19] (p. 103). This representative feature is considered a critical success factor for public spaces $[5,20,21]$.

While such urban squares promoting people's social exchange received little attention for a certain period of time from the early- to mid-20th century when the modernist movement greatly influenced cities around the world [12,22,23], the recent paradigm shift in urban design toward valuing the social functions of public spaces has revived the interest in European urban squares, and the forms of the squares have spread worldwide as a type of public space for social activities.

\subsection{Design Elements of European Urban Squares}

Scholars suggested that the qualities of urban squares are affected by various physical design elements including the $\mathrm{D} / \mathrm{H}$ ratio ((the ratio of the width $(\mathrm{D})$ of a public space to the height $(\mathrm{H})$ of the surrounding buildings), square size and shape, façade details of surrounding buildings, pavement patterns, public arts, street furniture, landscaping, and dominant colors [15,24-27] as well as non-physical factors such as users' experiences of and knowledge about urban squares, activities and events, and their historical backgrounds and place identity [15,24]. Many scholars have emphasized the importance of the $\mathrm{D} / \mathrm{H}$ ratio, square size, and façade details, in particular, and made various design suggestions based on European squares [1,3,15,26,28-30]. 
Researchers have suggested that the $\mathrm{D} / \mathrm{H}$ ratio is an important design element for the "sense of enclosure" of an open space and have proposed optimal D/H ratios [21,28-32]; Alberti suggested as a $\mathrm{D} / \mathrm{H}$ ratio of 2/1, Lynch and Hack indicated $2 / 1$ and 3/1, and Jacobs defined a ratio greater than 2/1 (a larger $\mathrm{D} / \mathrm{H}$ ratio means a lower building height) $[21,29,30]$. These $\mathrm{D} / \mathrm{H}$ ratios do not match precisely but seem to demonstrate an implicit consensus that they should be greater than 1/1.

Scholars have been wary of overly large squares and have suggested an appropriate size for the creation of human-scale squares. For example, Sitte noted that the largest squares of ancient cities were, on average, narrower than $143 \mathrm{~m}$ wide and critiqued gigantic modern squares for their emptiness and detrimental effects on the surrounding buildings [5]. Similarly, Lynch and Hack pointed out that the smaller sides of the great squares of the past typically did not exceed $140 \mathrm{~m}$ [21]. Recently, Gehl also recommended that an urban square should be no longer than $100 \mathrm{~m}$ wide, positing that "the $100 \mathrm{~m}$ distance enables onlookers to stand on one corner and get a general view of what is going on in the square" [28] (p. 38). The maximum dimensions presented by these scholars have been commonly based on the human-scale, European square, keeping in mind the distance at which social interaction is possible.

Scholars have argued that façade details have both aesthetic and social effects. Regarding aesthetic impacts, Trancik posited that the details of surrounding building facades, including "transparency, opacity, openings, and surface ornaments", affect the character of a square [26] (p. 61), while Jacobs suggested that building facades should include some degree of complexity to provide visual pleasure in public spaces [29]. Similarly, Whyte argued that overly orderly and uniform building façades could weaken the life of public spaces such as squares or streets, particularly criticizing the blank walls of the megastructures that are common in modern cities [33]. In terms of social impact, Gehl [28] (p. 81) suggested that open and active building façades significantly affect people's activity patterns and the appeal of urban public spaces. In particular, Hadelich emphasized the aspect of social control, saying, "Urban squares with buildings whose facades and entrances open onto the square at regular intervals generally offer the greatest sense of security" [34] (p. 9).

Recently, several studies have attempted to empirically test theories or principles involving these design elements. For example, Kim compared the effects of the D/H ratio, square size, and façade design on the qualities of urban squares using 2D computer-simulated images [35], whilst Kim and Kim examined the optimal $\mathrm{D} / \mathrm{H}$ ratios for urban squares proposed by urban theorists using immersive VR simulation [36]. Though these studies have made important academic contributions by providing empirical evidence regarding these design principles-which had previously primarily relied on experts' experience and intuition - the generalization of their findings is limited because they did not address the potential effects of users' perception, which may vary depending on their living environments.

\subsection{Application of European Urban Squares to Cities with Different Contexts}

Outside of Europe, open spaces similar to European squares were historically rare [22,23], and their social and economic functions have been accommodated by other types of public spaces such as streets [6] and bazaars [8,14]. However, as aforementioned, with the recent paradigm shift in urban design have the forms of European urban squares been actively introduced in cities outside Europe. Due to socio-cultural differences related to the living environment, however, urban square use in non-European contexts differs in some respects. For example, the urban squares of modern Chinese cities have been used to highlight the government's political achievements [37] as well as for social activities such as "urban dance" [38]. These differences in the activities in urban squares may result from the fact that the shape of the square, created in line with European contexts, is perceived differently by non-European urbanites. While people adapt to a given environment over time, spaces designed with consideration of people's different perceptions and preferences may enrich their lives. Therefore, to design urban squares that accommodate the needs of people who have lived in different environments, we must understand how they perceive the design elements of these squares. 
Regarding the differences among people in their spatial perceptions, many scholars in other fields have long explored the various subjects. For example, Richard Nisbett explored how Asian and Western people perceive and think differently [39]. Heath also mentioned culture as the determiner for how individuals perceive urban environments [40]. Particularly, regarding spatial perception, Saulton et al. [41] concluded that spatial perception and cognitive processes are rooted in cultural backgrounds, based on a psychophysical experiment to investigate the differences in spatial perception between German and South Korean people. In the urban planning and design field, scholars have also examined differences in environmental perceptions and preferences related to people's socio-cultural experiences in terms of landscapes [42,43], parks [44], urban streets [43], and colors [45]. For example, in his review of cross-cultural studies in recreation, Allison [44] recommended that the ways in which different environmental settings are perceived by different cultures should be systematically addressed. As Allison suggested, urban design principles for European urban squares should be also tested before applying them to different contexts, and such an examination is the main purpose of this study.

\section{Data and Methods}

\subsection{Outline of the Experimental Design and Analytical Framework}

This study investigates the differences among people having different environmental experiences in the perceptions of urban square qualities. For this purpose, we first conducted a visual assessment survey-type experiment with 100 participants who had lived in a variety of living environments using eight IVR-based urban square models with different $\mathrm{D} / \mathrm{H}$ ratios, sizes, and façade details. In the experiment, participants were asked to experience the modeled urban squares and score them using a nine-point Likert scale for each identified quality.

Next, using the data from this experiment, we conducted two-step statistical analysis. The first-phase analysis used multiple regression models to test the impact of participants' characteristics and the three urban square design elements on perceived qualities. In particular, the first-phase analysis aimed to test the potential impact of variables related to participants' living environments that were classified by participants' national-, urban-, and residential-scale environments such as the regional origin (nationality), urbanity level of the hometown, and housing type.

In the second phase, we conducted conjoint analysis to identify the relative importance of various urban square design elements on the evaluation of the squares according to groups classified by living environment. Conjoint analysis is a stated-preference survey-based statistical technique that helps determine how people value different attributes [46]. Using a series of mathematical models, it enables people's subjective internal preferences to be objectified and quantified, thus helping estimate the relative importance of individual attributes. In this study, we used an approach more advanced than standard conjoint analysis in two respects. First, we incorporated conjoint analysis with simulated VR to allow participants to evaluate profile cards (i.e., combinations of three urban square design elements) more accurately. Simulated VR (VR generated by computer simulation) has the advantage of being able to manipulate the virtual environment according to research purposes [36] and is, therefore, generally used to create planned or designed realities with components that do not yet exist in design-related fields including architecture, landscape architecture, and urban design [47]. Moreover, it enables urban researchers to conduct controlled experiments that would be almost impossible in real urban environments [36]. Whereas traditional studies conducting conjoint analysis have employed text-based descriptions [48-51] or two-dimensional visual materials such as photographs $[52,53]$ in their profile cards, recent studies [54,55] have applied VR techniques as a visual aid to help respondents make accurate decisions and concluded that this approach was more valid due to its higher level of realism. Second, we developed a quasi-rank-based conjoint experiment to overcome the limitation of a general rank-based one. In a general rank-based conjoint analysis, respondents are asked to rank alternatives from best to worst. However, it is neither easy or reliable for respondents to rank many square models for various qualities in IVR environments. Hence, after asking the respondents to score each model for 
multiple qualities, we combined the scores of each quality variable and ranked the squares based on the total scores. Only when two or more squares had the same score were respondents themselves asked to rank the squares from worst to best. This approach can complement the limitation of multiple regression analyses, which do not reflect the general behavior of comprehensively recognizing and evaluating the various qualities of urban spaces. The following sub-sections present the (1) conjoint analysis design, (2) 3D modeling and VR conversion, and (3) visual assessment survey with IVR and the post hoc questionnaire survey.

\subsection{Conjoint Analysis Design and Key Test Variables}

Conducting an efficient and appropriate conjoint analysis requires careful consideration to determine the optimal number and level of attributes. The basic principle of conjoint analysis design is that attributes and their levels should be realistic and feasible, covering almost the whole range of possibilities [56] (p. 2), [57] (p. 13), [58] (p. 405). Meanwhile, the total number of attributes and their levels should be minimized to reduce respondents' burden. Although a larger number of attribute levels would lead to more detailed insights into attribute preferences, this necessitates a higher number of profile cards and increases the complexity of consistent responses [57] (p. 15), [48] (p. 41). When faced with too much information, respondents may adopt simplification strategies by resorting to a random pattern of evaluation [56] (p. 4). Lastly, the number of levels across all attributes should be balanced to avoid a potential "number-of-levels effect", a tendency in which the attributes with more levels are more likely to be given higher importance than those with fewer levels [56,59]. As such, attributes and their levels should be rooted in appropriate theory.

Based on these principles, we selected three attributes of urban squares as key test variables in both our conjoint and multiple regression analyses: the $\mathrm{D} / \mathrm{H}$ ratio, square size, and façade detail. Other physical elements of urban squares, such as the functional mix of surrounding buildings, pavement pattern and design, dominant colors, public arts, and monuments, may also affect people's perceptions and preferences. Additionally, non-physical characteristics of urban squares including the activities and events within them, their historical background, and place identity may be another determiner. However, these non-physical attributes were not considered in this study, which instead aimed to reveal implications for the physical design principles of urban squares. Thus, among the various physical elements, we selected the three factors that influence people's perceptions of urban square qualities that have been suggested by many urbanists, as discussed in Section 2.2. Nevertheless, this limited number of attributes may represent a shortcoming of this study.

The level of each attribute was also determined based on extant literature. Regarding the $\mathrm{D} / \mathrm{H}$ ratio, we considered the boundary value problems and decided on 2, 4, and 8 as specific levels. These values were obtained from our previous study, which empirically suggested that $\mathrm{D} / \mathrm{H}$ ratios of 4-5 are optimal for urban squares [36]. We regarded 4 as the mid-level value, and half (2) and double (8) as the bottom- and top-level values, respectively. Regarding square size, two attribute levels ( $25 \times$ 25 and $50 \times 50 \mathrm{~m}$ ) were chosen within the ranges considered to be human scale. Smaller squares $(25 \times 25 \mathrm{~m})$ can be considered neighborhood community spaces, while larger ones $(50 \times 50 \mathrm{~m}) \mathrm{can}$ be considered neighborhood community spaces or the civic centers of small towns. According to Gehl, people usually recognize another person at approximately $50-70 \mathrm{~m}$ and accurately read facial expressions and dominant emotions at about 22-25 m [28] (p. 34). As such, in these human-scale squares, people can experience varying degrees of social interaction, such as observing others' activities, engaging with friends, and more intimate communication. The façade details of the surrounding buildings were given only two levels, "monotonous" and "complex", because it was considered easier for respondents to choose from clearly contrasting alternatives. Regarding the visual complexity of building facades, Jacobs suggested that a proper degree of visual complexity is required for the quality of public spaces [29] (p. 282); therefore, we assumed that complex façades were theoretically more desirable than monotonous ones. Many traditional European squares, which are the prototypes of urban squares, are surrounded by buildings with complex façade details, and their complexity is 
expressed via the design elements that Jacobs suggested, such as cornice lines, balconies, and details at the tops of windows [29] (pp. 281-285).

Within these attribute levels, the maximum number of environments (i.e., combinations) should be 12; however, a large number of profile cards increases the burden on respondents and the duration of the survey (in particular, in the case of VR-based experiments), which can diminish the consistency of the ratings [60]. Therefore, fractional factorial design was used to reduce the number of alternatives. The orthogonal array function in SPSS allowed us to calculate the minimum number of required profiles without missing the value of each variable once. Table 1 shows the eight profile cards used for conjoint analysis.

Table 1. Profile cards for conjoint analysis.

\begin{tabular}{ccccc}
\hline ID & $\begin{array}{c}\text { D/H } \\
\text { Ratio }\end{array}$ & Size & $\begin{array}{c}\text { Number of Stories of Surrounding Buildings } \\
\text { Determined by }\end{array}$ & F/H Ratio and Size \\
\hline $\mathbf{1}$ & 2 & $25 \times 25 \mathrm{~m}$ & 4 & Complex \\
$\mathbf{2}$ & 8 & $50 \times 50 \mathrm{~m}$ & 2 & Complex \\
$\mathbf{3}$ & 8 & $25 \times 25 \mathrm{~m}$ & 1 & Monotonous \\
$\mathbf{4}$ & 2 & $50 \times 50 \mathrm{~m}$ & 8 & Monotonous \\
$\mathbf{5}$ & 4 & $50 \times 50 \mathrm{~m}$ & 4 & Monotonous \\
$\mathbf{6}$ & 4 & $25 \times 25 \mathrm{~m}$ & 2 & Complex \\
$\mathbf{7}$ & 2 & $25 \times 25 \mathrm{~m}$ & 4 & Monotonous \\
$\mathbf{8}$ & 2 & $50 \times 50 \mathrm{~m}$ & 8 & Complex \\
\hline
\end{tabular}

Note: The height of each story was set to $3.125 \mathrm{~m}$ for ease of modeling.

\subsection{Modeling and VR Conversion}

We used SketchUp 2016 (Trimble Inc., Sunnyvale, CA, USA) to design 3D models of eight urban squares with different combinations of attribute levels for the $\mathrm{D} / \mathrm{H}$ ratio, square size, and façade detail. Modeling the first two attributes was easy due to their objective dimensions; however, contrastingly, façade detail is a subjective attribute. Accordingly, the models referred to Jacobs' descriptions and example sketches of "monotonous" and "complex" façade details (Figure 1). He described a complex façade as having rich spatial patterns and textures and protruding surfaces, whereas monotonous façades avoid details and contradictions [29]. Other than these three attributes, all the square components were identically designed to maintain consistency, thereby facilitating easier comparison. Participants were informed of this detail during the experiment.

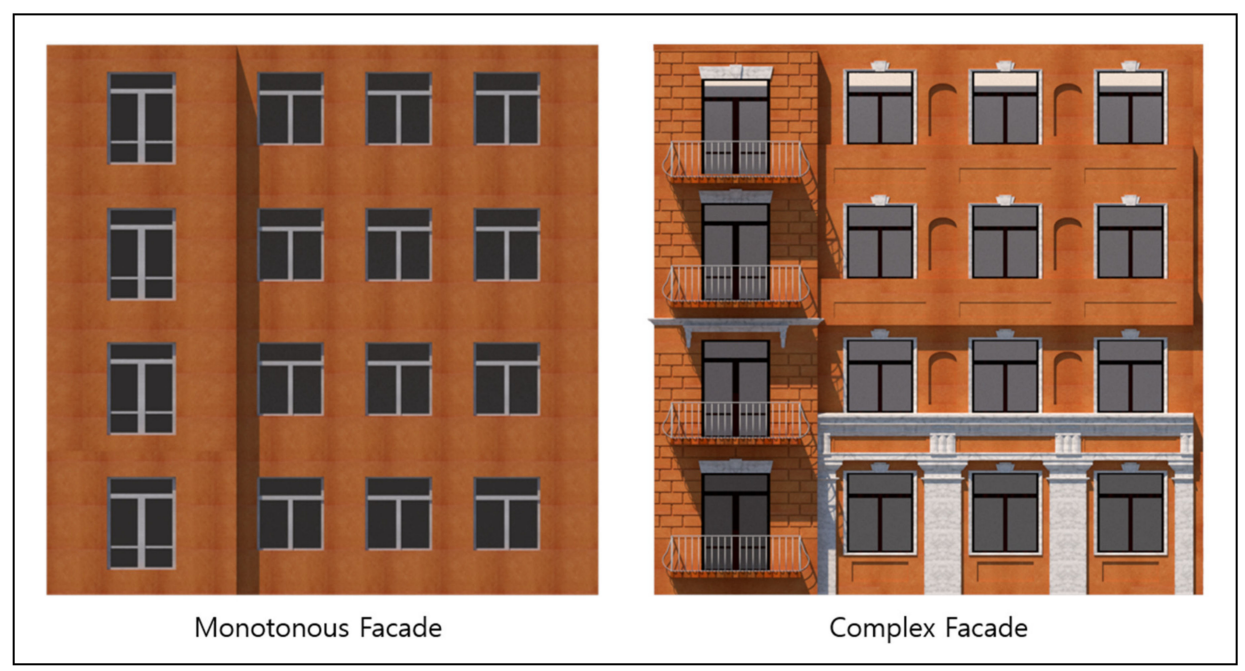

Figure 1. "Monotonous" and "complex" façades applied in the immersive virtual reality (IVR) simulation for the experiment. 
Kubity (https://www.kubity.com/) was used for the VR conversion of the eight square models, which converted the 3D models made in SketchUp into VR. This program allows users to experience 3D models at eye level via head-mounted display (HMD) devices.

\subsection{Visual Assessment Survey with IVR and Variables}

\subsubsection{Participants}

Participants were recruited using a snowball sampling process conducted between September 2019 and May 2020. To avoid extreme heterogeneity in the snowball sampling, the target population was limited to undergraduate and graduate university students in the Seoul Metropolitan Area. In total, 100 students of various nationalities were recruited for the experiment. The Korean participants were mostly recruited from undergraduate and graduate courses of the Department of Urban Design and Studies at Chung-Ang University (CAU). The snowball sampling process for foreign participants started with students from the Urban Development and Policy Master's Program at CAU and the Master of Urban Administration and Planning at the University of Seoul, which are both international scholarship programs supported by the Korea International Cooperation Agency and Seoul Metropolitan Government. All these participants provided informed consent.

The experiment's sample size of 100 participants is not considered small among VR studies. In Schneider et al., a review of 87 such studies showed that the average sample size was just 69.5 people [61]. The sample size of the present study was also sufficiently large to apply conjoint analysis [62] (p. 21). However, due to the limited population cohort (i.e., university students), we regard our experiment as an exploratory study applying novel methodology rather than a confirmatory study. Table 2 shows participants' characteristics related to living environments, as well as the descriptive statistics of other variables.

\subsubsection{Visual Assessment Survey with IVR and Dependent Variables (Perceived Qualities of Urban Squares)}

To measure the perceived qualities of urban squares (i.e., dependent variables), a visual assessment survey experiment with IVR was conducted for each participant under the guidance of experimental assistants who had been pre-trained for the procedure. The assistants initially explained the potential side-effects associated with the use of the VR HMD (e.g., dizziness) and the experiment's aims and procedure. Participants were then asked to sign a consent form to confirm their agreement to participate. The assistants guided participants in putting on and adjusting the HMD to fit securely and monitored their safety while wearing it.

Participants were asked to use the HMD to learn how to select and enter a square designated by the assistant. This warm-up process was necessary for two reasons. First, we needed to ensure that the participants clearly understood the number assigned to each profile card and their arrangement within the IVR environment, since the main experiment required sequential completion (according to instructions from the assistants) corresponding to predetermined random numbers. Second, the process served to familiarize the participants with the new technology, in an effort to obtain more valid responses [63-65].

In the main experiment, each participant was asked to select a number between 1 and 100 that contained a randomly predetermined survey order for the eight squares. The participant then experienced the eight squares according to her/his survey order. This approach aimed to neutralize any potential effect of the order in which the squares were presented [66]. Next, while experiencing each square within the IVR, participants were asked to rate the qualities of the squares on a nine-point Likert scale. The qualities comprised two intuitive qualities (coziness and openness), behavioral suitability for two social activities (gathering informally with friends and holding formal events), and the overall goodness of the urban square. These were derived from the eight qualities of an urban square tested in our previous studies [35,36], which are four intuitive qualities (openness, coziness, magnificence, and dauntingness), behavioral suitability for three activities, and overall goodness. Among these eight 
qualities, we excluded two elements (magnificence and dauntingness) since Kim and Kim revealed that both elements showed natures distinct from those of the others [36]. In addition, among the behavioral suitability variables, we excluded "suitability for optional activity" because we believed it could be difficult for participants to distinguish the squares' suitability for optional activity from that for informal social activity. In fact, Kim and Kim empirically showed that the results for both activities are very similar [36] although Gehl distinguished between them [67]. Thus, we employed only five properties of good urban squares as dependent variables in the analysis.

The participants scored each of the five qualities for each square verbally while wearing the HMDs, and the experiment assistants transcribed their responses. This was because wearing and taking off the HMDs to respond could have reduced participants' concentration and lengthened the experiment duration, thereby increasing the potential risk of health problems. In particular, for questions about the squares' suitability for formal/informal activities, the assistants provided participants with narrative scenarios to embody relevant contexts for the ratings, as previously applied by Tabrizian et al. [68].

After each participant had completed their evaluations, the assistants summed their scores for the five qualities of each square and checked whether any scores tied. In the event of a tie, participants were required to re-experience the squares with the same total score and rank them from worst to best. In the experiment, $80 \%$ of the participants gave the same score for at least one pair of profile cards and, on average, 2.4 squares (alternatives) were further experienced to determine the final rankings. As a result, an average of 10.4 assessments per person were carried out to rank eight different urban squares (major: 8 times, additional: 2.4 times).

Oculus Go and Oculus Rift HMDs were used as visualization devices for the IVR experience (Figure 2). Using a controller, participants could move and turn through $360^{\circ}$ to view and experience the virtual squares. The experiment was limited to $20 \mathrm{~min}$ for each participant (approximately 2 min per square) to avoid long exposure to the IVR environment, which could increase negative side-effects.

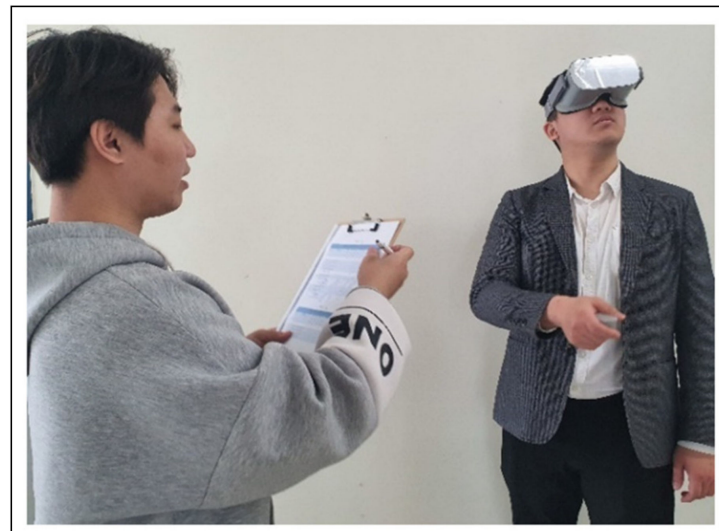

(a)

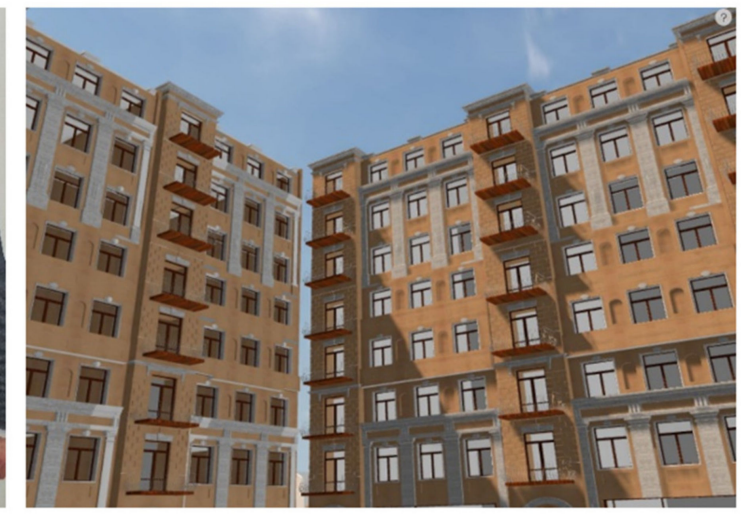

(b)

Figure 2. The IVR experiment process: (a) a snapshot of the experiment; (b) a sample image of a simulated IVR square.

\subsubsection{Post Hoc Questionnaire Survey and Control Variables}

After completing each participant's visual assessment survey, a post hoc questionnaire survey was conducted to control for participants' socio-demographic characteristics. As discussed in Section 2, the living environment is a critical factor that may affect individual perceptions of urban squares as well as preference for specific design elements. Accordingly, the multiple regression models included national-, urban-, and residential-scale living environments, such as the regional origin (nationality), urbanity level of the hometown, and housing type. These control variables were also considered in the conjoint analysis for classifying participants according to their living environments. 
First, to control for participants' nationalities, four dummy variables-African, Asian (except Korea), European, and Central and South American countries-were used, with Korea as the reference group. Second, we controlled for the urbanity level of where participants grew up, which was classified using the New Urbanists' Transect Plan concept. To collect this information, we presented six diagrams and sample images (from natural to urban core zone) and asked participants to choose which best described where they grew up (Figure 3). In the model, four dummy variables (suburban, general urban, urban center, and urban core zone) were applied with a combined natural-rural zone variable that functioned as a reference group. Lastly, the housing type (high- or low-rise) of each participant's most recent residence in their home country was also controlled for as a living environment variable since this could have affected their perceptions of the building heights and public spaces.

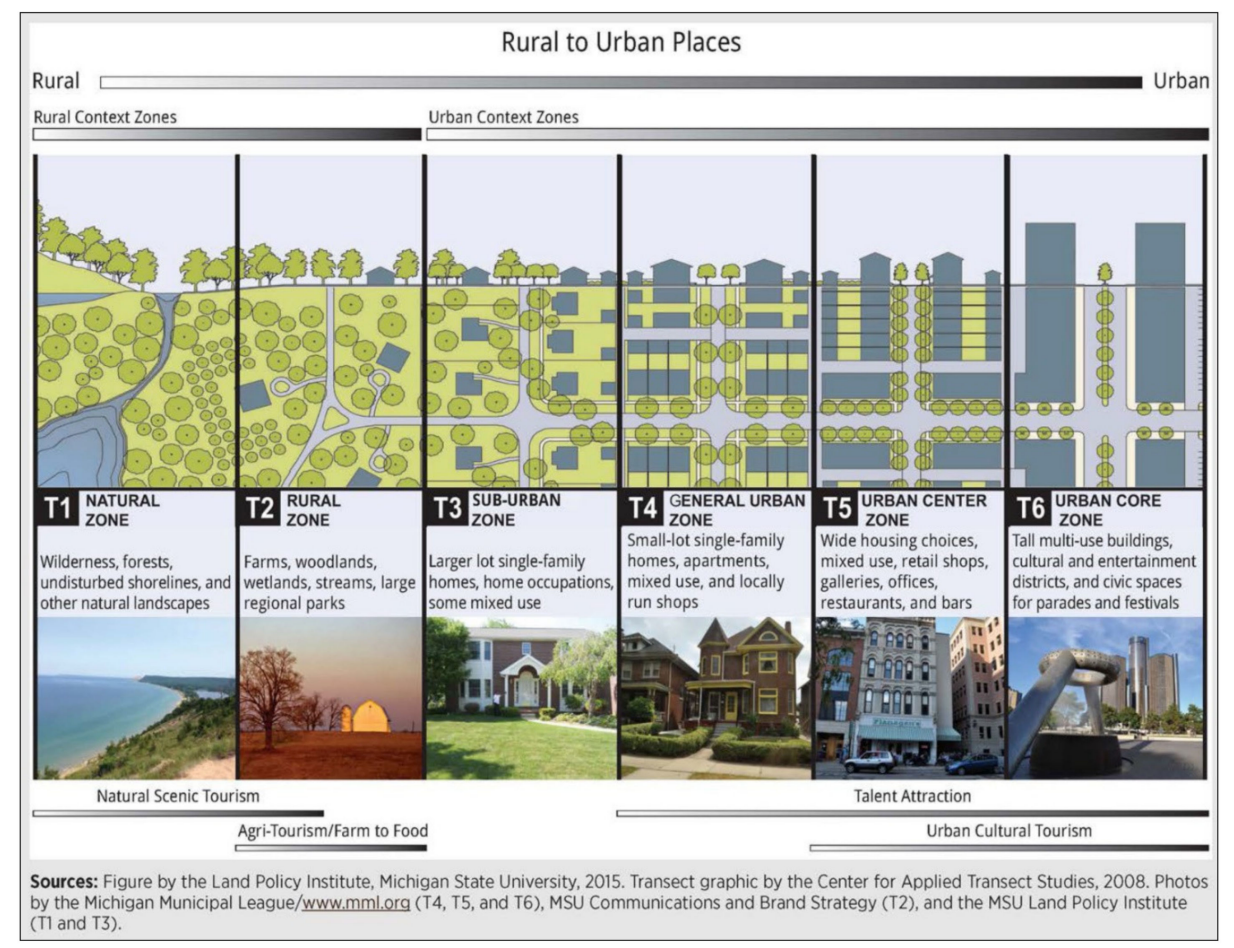

Figure 3. Transect diagrams and sample images (source: Michigan State University, Understanding the urban transect, https://www.canr.msu.edu/news/understanding_the_urban_transect, 2019.09.25.).

Participants were also asked to provide their basic personal details, including degree major, age, gender, university, and previous experience with IVR. These individual characteristics were mostly controlled for in previous studies [36,69-71]. We also applied an HMD-type variable to control for potential bias stemming from the experiment devices. Lastly, the survey order of the profile cards randomly assigned to each participant was applied for each participant to control for the potential "order effect" [66,72].

Data from the visual assessment and post hoc questionnaire surveys comprised 800 records (100 respondents $\times 8$ profile cards) for each dependent variable. Table 2 illustrates the variables' descriptive statistics. 
Table 2. Descriptive statistics of variables.

\begin{tabular}{|c|c|c|c|c|}
\hline Category & Variables & $\mathbf{N}$ & $\begin{array}{c}\text { Mean } \\
\text { (Ratio) }\end{array}$ & $\begin{array}{c}\text { Standard } \\
\text { Deviation }\end{array}$ \\
\hline \multicolumn{5}{|c|}{ Perceived qualities of urban squares (dependent variables) } \\
\hline \multirow{2}{*}{ Intuitive qualities } & Coziness & 800 & 5.425 & 2.170 \\
\hline & Openness & 800 & 5.400 & 2.353 \\
\hline \multirow[t]{2}{*}{ Behavioral suitability for: } & Informal gatherings & 800 & 5.521 & 2.128 \\
\hline & Formal events & 800 & 4.814 & 2.207 \\
\hline \multirow[t]{2}{*}{ Overall goodness } & Overall goodness & 800 & 5.446 & 2.065 \\
\hline & Living environment variables & & & \\
\hline \multirow[t]{5}{*}{ Nationality (continent) } & Korea (ref. group) & 100 & 0.500 & 0.503 \\
\hline & African countries & 100 & 0.130 & 0.338 \\
\hline & Asian countries except Korea & 100 & 0.250 & 0.435 \\
\hline & Central and South American countries & 100 & 0.070 & 0.256 \\
\hline & European countries & 100 & 0.050 & 0.219 \\
\hline \multirow[t]{5}{*}{ Urbanity level of hometown } & Natural and rural (ref. group) & 100 & 0.130 & 0.338 \\
\hline & Suburban & 100 & 0.150 & 0.359 \\
\hline & General urban & 100 & 0.220 & 0.416 \\
\hline & Urban center & 100 & 0.390 & 0.490 \\
\hline & Urban core & 100 & 0.110 & 0.314 \\
\hline Housing type & High-rise building (ref. = low-rise building) & 100 & 0.480 & 0.502 \\
\hline \multicolumn{5}{|c|}{ Other individual characteristics and control variables } \\
\hline \multirow[t]{4}{*}{ Major } & Urban studies (ref. group) & 100 & 0.630 & 0.485 \\
\hline & Architecture & 100 & 0.070 & 0.256 \\
\hline & Arts and social science & 100 & 0.150 & 0.359 \\
\hline & Science and engineering & 100 & 0.150 & 0.359 \\
\hline Gender & Female & 100 & 0.380 & 0.488 \\
\hline \multirow[t]{3}{*}{ Age (years) } & 21-25 (reference group) & 100 & 0.530 & 0.502 \\
\hline & $26-30$ & 100 & 0.270 & 0.446 \\
\hline & $\geq 31$ & 100 & 0.200 & 0.402 \\
\hline \multirow[t]{3}{*}{ University } & Chung-Ang University (ref. group) & 100 & 0.800 & 0.402 \\
\hline & University of Seoul & 100 & 0.150 & 0.359 \\
\hline & Yonsei University & 100 & 0.050 & 0.219 \\
\hline IVR experience & Have experienced & 100 & 0.610 & 0.490 \\
\hline \multirow[t]{2}{*}{ HMD type } & Oculus Go (ref. group) & 100 & 0.560 & 0.499 \\
\hline & Oculus Rift & 100 & 0.440 & 0.499 \\
\hline
\end{tabular}

\section{Analysis Results}

\subsection{Multiple Regression Analyses}

Table 3 shows the results of the multiple regression analyses for the five qualities of urban squares measured using a nine-point Likert scale. In general, the models showed that the three key variables were significantly associated $(p$-value $<0.1)$ with the perceived qualities of urban squares, after considering other factors.

First, while "D/H ratio" was negatively associated with "coziness", it was positively associated with the other four dependent variables. This result implies that lower surrounding buildings are generally preferred; however, in terms of "coziness", people might consider the need for vertical elements to secure a sense of enclosure to some extent. Since the relationship may not be linear, this needs to be re-examined using conjoint analysis. Second, "square size" was significantly associated only with behavioral suitability variables, and their signs conflicted with each other, meaning that participants preferred larger squares for formal events and smaller squares for informal gatherings. Lastly, "complex façade" was positively and significantly associated with all the qualities of urban squares. 
Table 3. Multiple regression models of the five qualities of urban squares.

\begin{tabular}{|c|c|c|c|c|c|c|c|c|c|c|}
\hline & \multicolumn{4}{|c|}{ Intuitive Qualities } & \multicolumn{4}{|c|}{$\begin{array}{l}\text { Behavioral Suitability for } \\
\text { Social Activities }\end{array}$} & \multicolumn{2}{|c|}{ Overall Goodness } \\
\hline & \multicolumn{2}{|c|}{ Coziness } & \multicolumn{2}{|c|}{ Openness } & \multicolumn{2}{|c|}{ Informal Gatherings } & \multicolumn{2}{|c|}{ Formal Events } & \multirow[b]{2}{*}{ B } & \multirow[b]{2}{*}{$p$} \\
\hline & B & $p$ & B & $p$ & B & $p$ & B & $p$ & & \\
\hline $\mathrm{D} / \mathrm{H}$ ratio & -0.079 & $0.008^{* * *}$ & 0.264 & $0.000^{* * *}$ & 0.088 & $0.002 * * *$ & 0.125 & $0.000^{* * *}$ & 0.133 & $0.000^{* * *}$ \\
\hline Large square & -0.087 & 0.553 & -0.201 & 0.184 & -0.698 & $0.000 * * *$ & 0.676 & $0.000 * * *$ & 0.043 & 0.746 \\
\hline Complex façade & 0.704 & $0.000 * * *$ & 0.801 & $0.000 * * *$ & 0.541 & $0.000 * * *$ & 0.641 & $0.000 * * *$ & 1.245 & $0.000 * * *$ \\
\hline \multicolumn{11}{|l|}{ Nationality (ref. = Korea) } \\
\hline African & 0.115 & 0.767 & -0.285 & 0.478 & 0.388 & 0.301 & -0.737 & $0.058^{*}$ & -0.312 & 0.376 \\
\hline Asian (except Korea) & -0.487 & 0.101 & -0.219 & 0.476 & -0.191 & 0.505 & -0.604 & $0.043 * *$ & -0.572 & $0.034^{* *}$ \\
\hline C/S American & -0.050 & 0.895 & -0.394 & 0.313 & -0.085 & 0.816 & -0.845 & $0.025 * *$ & -0.741 & $0.030 * *$ \\
\hline European & -0.578 & 0.184 & 0.074 & 0.870 & -0.655 & 0.119 & -0.382 & 0.380 & -0.522 & 0.185 \\
\hline \multicolumn{11}{|l|}{$\begin{array}{l}\text { Urbanity level of hometown } \\
\text { (ref. = natural and rural) }\end{array}$} \\
\hline Suburban & -0.096 & 0.762 & 0.121 & 0.713 & 0.358 & 0.242 & -0.157 & 0.621 & -0.121 & 0.673 \\
\hline General urban & -0.285 & 0.328 & 0.527 & $0.081 *$ & 0.298 & 0.291 & -0.191 & 0.514 & 0.062 & 0.815 \\
\hline Urban center & 0.027 & 0.922 & -0.167 & 0.563 & -0.074 & 0.783 & -0.499 & $0.074^{*}$ & -0.531 & $0.036^{* *}$ \\
\hline Urban core & 0.130 & 0.702 & -0.478 & 0.174 & 0.211 & 0.521 & -0.742 & $0.030 * *$ & -0.787 & $0.011 * *$ \\
\hline Housing type (high-rise $=1$ ) & -0.178 & 0.363 & 0.598 & $0.003^{* * *}$ & 0.136 & 0.471 & 0.031 & 0.873 & 0.238 & 0.178 \\
\hline \multicolumn{11}{|l|}{ Major (ref. = urban studies) } \\
\hline Architecture & -1.360 & $0.000^{* * *}$ & -0.536 & 0.160 & -1.515 & $0.000^{* * *}$ & -0.721 & $0.051^{*}$ & -1.138 & $0.001^{* * *}$ \\
\hline Arts and social science & -1.179 & $0.000 * * *$ & -0.596 & $0.021 * *$ & -0.977 & $0.000 * * *$ & -0.620 & $0.013^{* *}$ & -0.405 & $0.073^{*}$ \\
\hline Science and engineering & -0.571 & $0.028^{* *}$ & 0.010 & 0.971 & -0.430 & $0.086^{*}$ & -0.209 & 0.420 & -0.209 & 0.375 \\
\hline Gender $($ female $=1)$ & -0.218 & 0.192 & 0.234 & 0.177 & 0.226 & 0.161 & 0.027 & 0.873 & 0.473 & $0.002^{* * *}$ \\
\hline \multicolumn{11}{|l|}{ Age (ref. $=21-25)$ (years) } \\
\hline $26-30$ & 0.037 & 0.867 & -0.168 & 0.463 & -0.566 & $0.008^{* * *}$ & -0.482 & $0.029 * *$ & -0.068 & 0.736 \\
\hline$\geq 31$ & 0.506 & $0.067 *$ & -0.516 & $0.071 *$ & -0.950 & $0.000 * * *$ & -0.626 & $0.024 * *$ & 0.144 & 0.565 \\
\hline \multicolumn{11}{|l|}{ University (ref. = CAU) } \\
\hline University of Seoul & -0.748 & $0.033^{* *}$ & 0.040 & 0.911 & -0.141 & 0.677 & -0.142 & 0.686 & -0.415 & 0.190 \\
\hline Yonsei University & 0.295 & 0.526 & -1.039 & $0.031 * *$ & 0.193 & 0.667 & -0.018 & 0.970 & 0.280 & 0.507 \\
\hline IVR experience $(\mathrm{Y}=1)$ & 0.174 & 0.333 & -0.472 & $0.011^{* *}$ & -0.112 & 0.519 & -0.535 & $0.003^{* * *}$ & 0.099 & 0.543 \\
\hline HMD type (Oculus Rift = 1) & 0.958 & $0.000 * * *$ & 0.919 & $0.000 * * *$ & 0.814 & $0.000 * * *$ & 0.786 & $0.000 * * *$ & 0.940 & $0.000 * * *$ \\
\hline Survey order of the profile cards & -0.039 & 0.222 & -0.003 & 0.933 & -0.014 & 0.647 & -0.015 & 0.635 & -0.011 & 0.707 \\
\hline (Constant) & 5.783 & $0.000 * * *$ & 3.985 & $0.000^{* * *}$ & 5.466 & $0.000^{* * *}$ & 4.796 & $0.000 * * *$ & 4.322 & $0.000 * * *$ \\
\hline Adj. R-Square & 0.103 & & 0.181 & & 0.129 & & 0.130 & & 0.185 & \\
\hline
\end{tabular}


The three sets of living environment variables showed significant associations with certain qualities of urban squares. From the results, we found some clues that the living environments can affect people's spatial perceptions and preferences. First, in terms of "suitability for formal events", some of nationality and urbanity level of hometown variables were significantly associated with the perceived quality of urban squares. This implies that the types of formal events held at a square may differ by culture [37], even though everyday informal activities at squares are not dissimilar between them. Second, regarding housing type, participants living in high-rise apartments tended to give higher scores for the quality of openness than those living in low-rise houses. As such, people's living environments might affect their perception of and preferences for urban square design. Thus, a series of stratified conjoint analyses according to participants' living environments were then conducted.

The results for the control variables were also theoretically and empirically reliable $[35,36]$. The control variables related to the experiment conditions, including "university" and "survey order", showed insignificant or inconsistent results. However, contrary to our expectations, the participants who used the Oculus Rift HMD gave higher scores for all quality variables than those who used Oculus Go. Although Kubity-our VR conversion software-supports both devices, differences in the resolution between them are expected to have affected this result.

\subsection{Conjoint Analyses}

\subsubsection{Results of Full Sample Model and Stratified Models by Regional Origin}

Table 4 presents the results of the quasi-rank-based conjoint analyses for the full samples and the stratified samples by regional origin. In the table, the "importance" columns show the relative importance of each attribute. The results of the full sample model revealed that the $\mathrm{D} / \mathrm{H}$ ratio was the most dominant attribute $(44.020 \%)$, and the importance of façade detail $(29.999 \%)$ appeared slightly larger than that of square size (25.981\%). The stratified conjoint analyses for the five groups also showed similar trends, although the sample sizes of some groups were too small to confirm their trends. For the façade detail and square size, only the European group, which had the smallest sample, showed exactly the opposite trend to the others.

Table 4. Results of conjoint analysis by participant origin.

\begin{tabular}{ccccccc}
\hline & Korean & African & Asian & $\begin{array}{c}\text { Central and } \\
\text { South } \\
\text { American }\end{array}$ & European & $\begin{array}{c}\text { Full } \\
\text { Sample }\end{array}$ \\
\hline Attribute importance & & & & & & \\
D/H ratio & 46.139 & 38.715 & 42.517 & 44.676 & 46.138 & 44.020 \\
Square size & 25.441 & 26.038 & 28.270 & 19.653 & 29.399 & 25.981 \\
Façade detail & 28.420 & 35.247 & 29.212 & 35.671 & 24.462 & 29.999 \\
\hline Utilities (part-worth) & & & & & & -0.400 \\
D/H ratio 2 & -0.913 & -0.179 & -0.568 & -1.333 & -0.753 \\
D/H ratio 4 & 0.482 & -0.083 & 0.228 & 0.452 & -0.500 & 0.302 \\
D/H ratio 8 & 0.432 & 0.263 & 0.340 & 0.881 & 0.900 & 0.452 \\
$25 \times$ 25 m square Size & -0.280 & 0.654 & 0.037 & -0.036 & 0.900 & 0.000 \\
$50 \times$ 50 m square Size & 0.280 & -0.654 & -0.037 & 0.036 & -0.900 & 0.000 \\
Monotonous façade & -0.780 & -0.885 & -0.852 & -1.143 & -0.750 & -0.837 \\
Complex façade & 0.780 & 0.885 & 0.852 & 1.143 & 0.750 & 0.837 \\
\hline \# of participants & 50 & 13 & 25 & 7 & 5 & 100 \\
\hline
\end{tabular}

Regarding the specific part-worth utility of each attribute level, the full sample model showed that the complex façade had the highest value (0.837). This means that the complex façade detail was preferred over any other elements included in the analysis. This tendency also similarly appeared in other stratified models. 
In the full sample model, the $\mathrm{D} / \mathrm{H}$ ratios 4 and 8 showed relatively large utilities, and the $\mathrm{D} / \mathrm{H}$ ratio 2 presented the second-lowest utility value. This result was consistent with the results of the regression analysis that respondents generally preferred urban squares surrounded by low-rise buildings in terms of most qualities. However, the stratified model results varied according to origin, although the sample sizes of some groups were quite small. In particular, whereas all other groups showed a consistent trend that a higher $\mathrm{D} / \mathrm{H}$ ratio (lower surrounding buildings) was preferred, the $\mathrm{D} / \mathrm{H}$ ratio 4 had the highest part-worth utility (0.482) among the Korean group. This result reconfirmed the finding of our previous study focused on Koreans, in which the optimal D/H ratios for urban squares appeared to be between 4 and 5 [36].

Both square sizes were equally preferred in the full sample model. However, the stratified models showed a great contrast between the origin groups: European and African participants preferred smaller squares, while the Korean participants preferred larger ones. Asian and Central and South American participants showed similar preferences for both square sizes. Lastly, all groups preferred complex façade details.

Among the groups, the Asian and Korean participants were expected to have the greatest socio-cultural similarities; however, they exhibited huge differences in their part-worth utility values. Rather, regarding the $\mathrm{D} / \mathrm{H}$ ratio, which had the highest importance, the results showed similarity between the African, Asian (except Korean), and Central and South American groups (i.e., the lower the surrounding buildings, the higher the preference). The similarity between these groups was also identified in the multiple regression models. However, it was difficult to find geographical common ground to interpret the three groups' similarities revealed in the analysis.

Hence, we sought potential characteristics other than origin that could have a meaningful impact on people's spatial perceptions and preferences and found that the level of economic development in the regional origin could be a plausible explanation. In fact, according to the four income levels defined by Rosling et al. [73], none of the countries classified as African, Asian (except Korean), or Central and South American in our data belong to the highest economic level (i.e., level 4 countries with more than USD 24,200 GDP per capita, adjusted for inflation), while Korea and the European countries did. Rosling et al. argued that the lifestyles of people who have similar economic status show similar patterns, regardless of their geographical locations [73]. Therefore, it can be tentatively inferred that urban environments in relatively underdeveloped countries, where there are not many high-rise buildings, can make people familiar with buildings of human scale and influence them to prefer squares surrounded by low-rise buildings. That is, the differences between groups may not be directly attributable to the regional origin, but to the living environment formed by the level of economic or urban development.

To confirm this inference, we compared the living environments experienced by participants in each group using Fisher's exact test. The results of the cross tabulation and Fisher's exact test in Table 5 show that Korean participants were more likely than African and other Asian participants to grow up in urbanized areas. Table 5 also suggests that Korean participants were more likely to live in high-rise buildings in their home towns (70\%), while most African, Asian, and Central and South American participants tended to live in low-rise housing (approximately 78\%). The results coincided with the above inference that the classification by regional origin in the analyses was highly related to the participants' living environments. Thus, we conducted additional stratified analyses based on participants' living environments. 
Table 5. Urbanity level and housing type by origin (results of Fisher's exact test).

\begin{tabular}{ccccccc}
\hline & Total & Korea & African & Asian & $\begin{array}{c}\text { Central and South } \\
\text { American }\end{array}$ & European \\
\hline T1-T2 & 13 & 3 & 3 & 6 & 0 & 1 \\
T3-T4 & 37 & 10 & 8 & 12 & 4 & 3 \\
T5-T6 & 50 & 37 & 2 & 7 & 3 & 1 \\
\hline Low-rise & 52 & 15 & 12 & 17 & 6 & 2 \\
High-rise & 48 & 35 & 1 & 8 & 1 & 3 \\
\hline N & 100 & 50 & 13 & 25 & 7 & 5 \\
\hline
\end{tabular}

Note: Urbanity levels T1 to T6 represent natural, rural, suburban, general urban, urban center, and urban core, respectively. The distribution of the urbanity level and housing type significantly varied across groups by regional origin at a 0.01 probability level.

\subsubsection{Results of the Stratified Models by Living Environment}

Table 6 and Figures 4 and 5 illustrate the stratified conjoint analysis results by the urbanity level of hometown and housing type. First, the results by urbanity level showed both similarities and dissimilarities between groups. The results of the T3-T4 (suburban and general urban) and T5-T6 (urban center and urban core) groups were generally similar, except for conflicting signs for square sizes. By contrast, the T1-T2 (natural and rural) groups showed distinctive patterns. Crucially, their importance score for square size was the largest among all sub-groups, which signified that they were more concerned with the size of the square in their evaluations than the other groups. The part-worth utilities for square size attributes also suggested that participants who grew up in natural and rural areas preferred smaller squares. With regard to the $\mathrm{D} / \mathrm{H}$ ratio, while city-born participants (T3-T6) showed distinctive preferences for a higher $\mathrm{D} / \mathrm{H}$ ratio, country-born participants (T1-T2) showed small differences (Figure 5). Country-born participants' lack of experience with various urban space characteristics may affect the absence of a particular preference for different levels of $\mathrm{D} / \mathrm{H}$ ratio (height of surrounding buildings).

Table 6. Results of conjoint analysis by living environment.

\begin{tabular}{ccccccc}
\hline & T1-T2 & T3-T4 & T5-T6 & $\begin{array}{c}\text { High-Rise } \\
\text { Housing }\end{array}$ & $\begin{array}{c}\text { Low-Rise } \\
\text { Housing }\end{array}$ & $\begin{array}{c}\text { Full } \\
\text { Sample }\end{array}$ \\
\hline Attribute importance & & & & & & \\
D/H ratio & 41.473 & 40.826 & 47.045 & 45.809 & 42.368 & 44.020 \\
Square size & 32.873 & 27.736 & 22.891 & 24.791 & 27.080 & 25.981 \\
Façade detail & 25.653 & 31.438 & 30.064 & 29.400 & 30.552 & 29.999 \\
\hline Utilities (part-worth) & & & & & & \\
D/H ratio 2 & 0.077 & -0.838 & -0.907 & -0.729 & -0.776 & -0.753 \\
D/H ratio 4 & 0.096 & 0.264 & 0.383 & 0.432 & 0.181 & 0.302 \\
D/H ratio 8 & -0.173 & 0.574 & 0.523 & 0.297 & 0.595 & 0.452 \\
$25 \times$ 25 m square size & 0.346 & 0.095 & -0.160 & -0.078 & 0.072 & 0.000 \\
$50 \times$ 50 m square size & -0.346 & -0.095 & 0.160 & 0.078 & -0.072 & 0.000 \\
Monotonous façade & -0.538 & -0.865 & -0.895 & -0.781 & -0.889 & -0.837 \\
Complex façade & 0.538 & 0.865 & 0.895 & 0.781 & 0.889 & 0.837 \\
\hline \# of participants & 13 & 37 & 50 & 48 & 52 & 100 \\
\hline
\end{tabular}

Note: Urbanity levels T1-T6 represent natural, rural, suburban, general urban, urban center, and urban core, respectively.

Second, the results by housing type generally showed similar trends in the differences between the Korean and other participants to the results shown in Table 4. However, the result regarding the $\mathrm{D} / \mathrm{H}$ ratio showed much clearer differences between high- and low-rise housing resident groups than those between the groups by origin. That is, the pattern showing the shape of a concave curve with 
a maximum value of 4 for the $\mathrm{D} / \mathrm{H}$ ratio (Figure 5) was more pronounced in the high-rise housing group than in the Korean group (Table 4). These results suggested that people living in high-rise buildings may prefer a moderate level of enclosure (i.e., a $\mathrm{D} / \mathrm{H}$ ratio of about 4), while low-rise building residents may prefer lower buildings surrounding the square (i.e., having a higher $\mathrm{D} / \mathrm{H}$ ratio). Low-rise building residents may prefer more open squares enclosed by low-rise buildings because they are more familiar with such environments. In other words, the familiarity level with urban spaces can affect place preferences. Together, these analysis results lead us to the conclusion that, rather than just their regions of origin, differences in the physical environment they have lived in may influence people's perceptions and preferences regarding the design elements of urban squares.

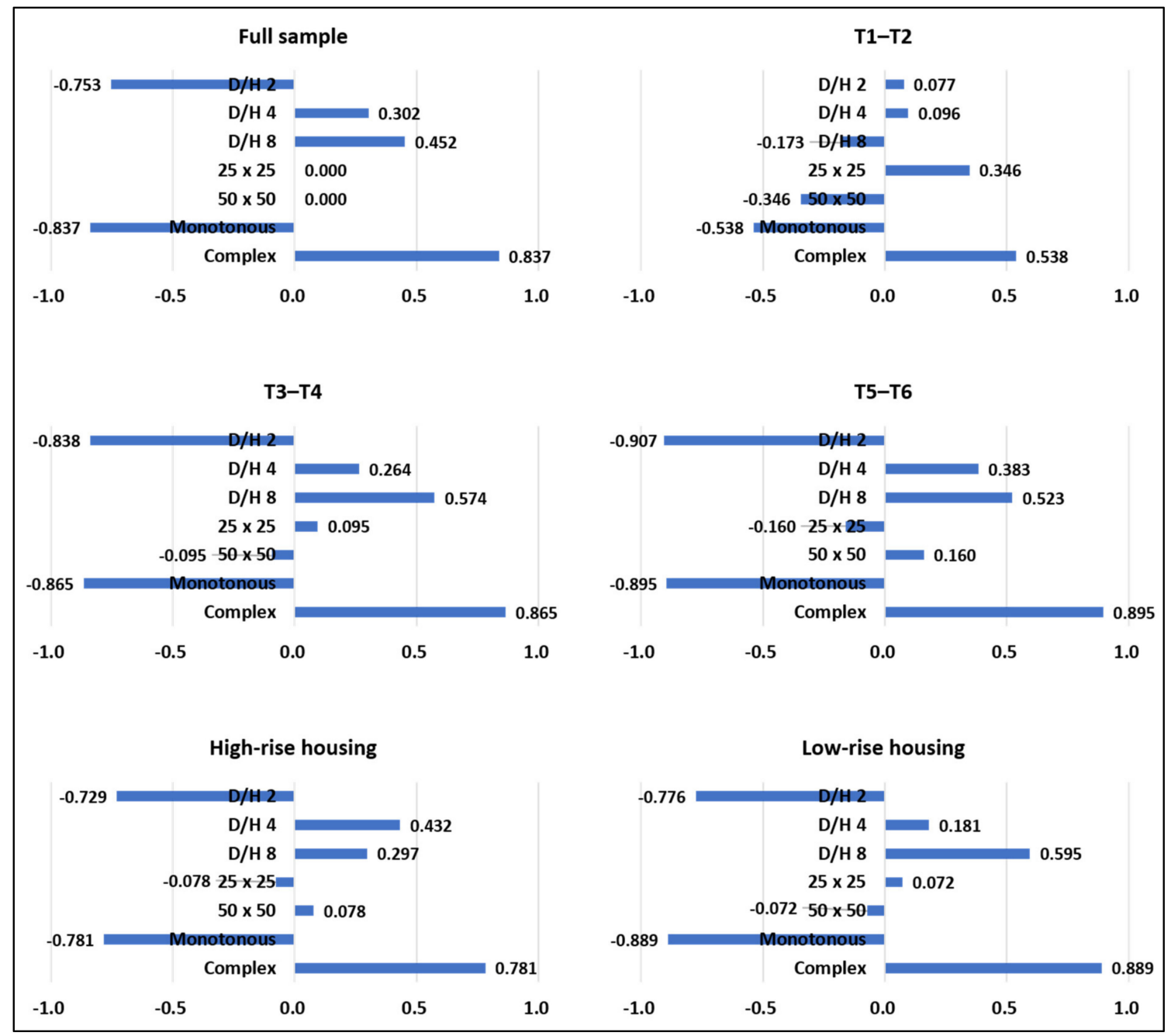

Figure 4. Part-worth utilities of groups by living environment. 


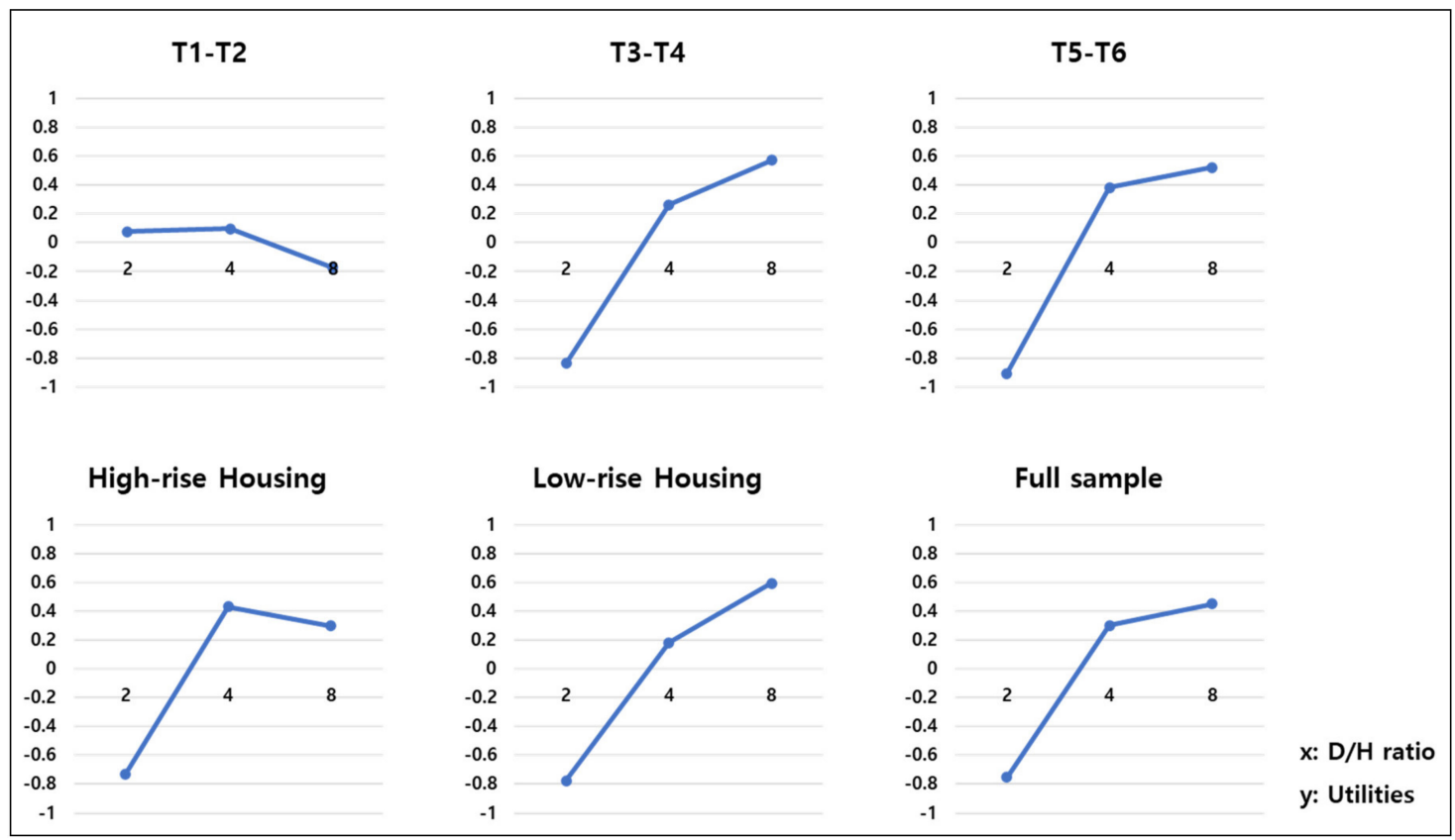

Figure 5. Part-worth utilities for $\mathrm{D} / \mathrm{H}$ ratio by sub-group.

\section{Conclusions}

This study examined the differences among people having different environmental experiences in perceptions of and preferences for design elements of an urban square by applying a series of IVR-aided conjoint analyses. From the analyses, we identified some similarities and differences among participants with different living environments. First, the $\mathrm{D} / \mathrm{H}$ ratio had the most dominant influence on the perception of the qualities among the three design attributes of urban squares irrespectively of participants' living environments. Our earlier study had already shown the influence of D/H ratios on perceptions of squares [35]; however, due to research method limitations, we were previously unable to grasp the relative importance of the $\mathrm{D} / \mathrm{H}$ ratio compared to that of other design elements. In particular, while participants living in high-rise buildings preferred a moderate level of enclosure (i.e., a $\mathrm{D} / \mathrm{H}$ ratio of 4), participants living in low-rise buildings preferred a higher $\mathrm{D} / \mathrm{H}$ ratio (i.e., lower surrounding buildings). In addition, participants who grew up in natural or rural areas lacked a particular preference for different $\mathrm{D} / \mathrm{H}$ ratios. Second, participants who lived in high-rise buildings or grew up in urbanized areas preferred larger squares than those who did not. Lastly, in all the stratified models, complex façades were highly preferred over monotonous façades, as anticipated $[26,29,35]$. Summing up these findings, we tentatively conclude that the degree of experience in diverse urban environments may affect people's familiarity with specific urban spaces and alter their spatial perceptions and preferences. However, extant studies have also supported the counterargument that people prefer unfamiliar landscapes [74,75], and, therefore, the present study merely augments the evidence in the body of existing literature on whether people prefer familiar cityscapes or vice versa.

This study suggests that participants' characteristics, in particular, those related to living environments, rather than regional origin, may be an important factor influencing spatial perception. We believe that these findings could contribute to improving urban spaces to suit peoples' needs, which may differ according to socio-cultural contexts. As aforementioned, urban design theories and principles based on European culture have often been uncritically adopted by the rest of the world [9]. However, the application of urban design without consideration of socio-cultural differences can make their lives uncomfortable, similar to wearing clothes that do not fit, and may also impede the continued development of culture. Urban designers should bear in mind such differences when designing urban squares or improving other urban public spaces. 
Another contribution of this study is its improvement of research methods that synthetically combines conjoint analysis and IVR technology. Conjoint experiments using visual materials enable more accurate research than conventional text-based approaches. In particular, the use of IVR as a visual aid can greatly enhance studies that require spatial experiences $[54,55]$. However, conjoint experiments using IVR pose difficulty in terms of execution compared to those using paper profile cards. In rank-based conjoint experiments, paper profile cards make comparing and ranking easy. However, if alternatives (profiles) are presented sequentially in the form of simulated IVR, not all alternatives can be experienced simultaneously, inevitably diminishing the accuracy of the task or increasing the experiment duration. In the case of choice-based conjoint experiments, the number of alternatives to experience greatly increases. Even though typical choice-based experiments have a similar number of trials to rank-based experiments, they present multiple alternatives (typically three to six) in a single task $[76,77]$. This approach is more likely to increase experiment duration, leading to potential health problems. Therefore, we developed a quasi-rank-based conjoint experiment as an alternative. This method, which combines rating- and rank-based experiment approaches, allows participants to experience and score all alternatives in the first evaluation and through an additional evaluation and give rankings only for alternatives with the same sum of scores. By clarifying the ranking of alternatives that did not differ much, we obtained benefits similar to those of choice-based experiments that accurately identify people's preferences. In fact, in the first evaluation, $80 \%$ of the participants gave the same score for at least one pair of profile cards, and on average, 2.4 squares (alternatives) had to be additionally experienced to determine the final rankings (an average of 2.4 additions per person). Thus, the limitations of conventional VR-based conjoint experiments were minimized by effectively conducting conjoint experiments with an average of 10.4 assessments, thus minimizing the time required to experience the simulated environments via VR devices. The chronic problem of rank-based experiments, in which participants find it difficult to rank the alternatives from just one experience of each VR environment, was also alleviated. The proposed IVR-aided quasi-rank-based conjoint analysis is expected to be a promising and sound research method, particularly for public space studies using VR.

However, despite the aforementioned contributions, this study has the following limitations. As noted throughout, only 100 students participated in our experiment. Although this sample size is relatively large among VR studies [61] and acceptable for conjoint analysis [62], our stratified model analysis required a larger sample size for better generalizability. Nevertheless, this study is meaningful in that it demonstrated that the uniform acceptance of design principles without any consideration of socio-cultural context might be problematic. Follow-up studies targeting specific groups sharing experiences in a common living environment could suggest how to design cities with consideration of socio-cultural context. In addition, like other research using VR, this study targeted a limited population cohort of university students, thus making generalizing our results difficult. Although avoiding extreme heterogeneity with the snowball sampling method was intended, the present research should be regarded as a pioneering study applying novel methodology, rather than a confirmatory study using a robust experiment design and rich data. Lastly, despite the various advantages of IVR-aided conjoint analysis, this method limits the number of attributes (i.e., design elements of urban squares) that can be analyzed simultaneously in an experiment. This is the common shortcoming of conjoint experiments; however, it becomes more critical when conducting experiments with IVR, as this study did. Although we developed a quasi-rank-based conjoint experiment to alleviate this problem, the experiment design only allowed up to three attributes to be included in the analysis. Due to this limitation, it is not appropriate to deduce general design principles, and, therefore, the contribution of this study is limited to demonstrating that people's preferences for design elements may vary depending on their living environments. Thus, follow-up studies considering more diverse factors, including physical and non-physical elements, of urban squares are needed. These limitations are all common shortcomings of studies using VR equipment, and it is expected that they can be 
overcome in future studies if the convenience of equipment utilization improves and the price of equipment decreases.

Author Contributions: S.K. and J.K. led and contributed equally to this research, and B.K. assisted in the research. Conceptualization, S.K. and J.K.; methodology, S.K. and J.K.; formal analysis, S.K. and B.K.; investigation, S.K., J.K., and B.K.; resources, S.K.; data curation, S.K. and B.K.; writing-original draft preparation, S.K. and J.K.; writing-review and editing, S.K. and J.K.; visualization, S.K. and J.K.; project administration, S.K.; funding acquisition, S.K.; supervision, S.K. and J.K. All authors have read and agreed to the published version of the manuscript.

Funding: This research was supported by the Chung-Ang University Graduated Research Scholarship in 2019 and the National Research Foundation of Korea (NRF) funded by the Ministry of Education, Science and Technology (NRF-2018R1C1B6008235).

Acknowledgments: The authors are grateful for the useful comments provided by the three anonymous reviewers.

Conflicts of Interest: The authors declare no conflict of interest.

\section{References}

1. Alexander, C.; Ishikawa, S.; Silverstein, M. A Pattern Language: Towns, Buildings, Construction; Oxford University Press: New York, NY, USA, 1977.

2. Lang, J.; Marshall, N. Urban Squares As Places, Links and Displays: Successes and Failures; Routledge: New York, NY, USA, 2016.

3. Lynch, K. Good City Form; MIT Press: Cambridge, MA, USA, 1984.

4. Marcus, C.C.; Francis, C. People Places: Design Guidlines for Urban Open Space; John Wiley \& Sons: Hoboken, NJ, USA, 1997.

5. Moughtin, C. Urban Design: Street and Square; Routledge: Abingdon, UK, 2003.

6. Kim, J. The square has finally become a 'square'! J. Environ. Stud. 2017, 59, 4-6.

7. Yeganeh, M.; Almasi, M.H. Socio-Economic Values and Architectural Features in Traditional Bazaars of Islamic Cites. Urban Manag. 2016, 15, 149-162.

8. Hakim, B.S. Arabic Islamic Cities Rev: Building and Planning Principles; Routledge: New York, NY, USA, 2013.

9. Piazzoni, M.F.; Banerjee, T. Mimicry in design: The urban form of development. J. Urban Des. 2018, 23, 482-498. [CrossRef]

10. Malik, A. After modernity: Contemporary non-western cities and architecture. Futures 2001, 33, 873-882. [CrossRef]

11. Mateo-Babiano, I.; Ieda, H. Theoretical discourse on sustainable space design: Towards creating and sustaining effective sidewalks. Bus. Strateg. Environ. 2005, 14, 300-314. [CrossRef]

12. Fishman, R. Urban Utopias in the Twentieth Century: Ebenezer Howard, Frank Lloyd Wright, and Le Corbusier; MIT Press: Cambridge, MA, USA, 1982.

13. Xie, Y.; Costa, F.J. Urban design practice in socialist China. Third World Plan. Rev. 1991, 13, 277. [CrossRef]

14. Schmidt, W.; Nzimande, A. Cultural differences in color/form preference and in classificatory behavior. Hum. Dev. 1970, 13, 140-148. [CrossRef]

15. Lennard, C.H.; Lennard, L. Genius of the European Square: Carmel; International Making Cities Livable Council: Carmel, CA, USA, 2008.

16. Mumford, L. The City in History: Its Origins, Its Transformations, and Its Prospects; Harcourt Brace \& Company: New York, NY, USA, 1961.

17. Kostof, S. The City Shaped: Urban Patterns and Meanings through History; Bulfinch Press: New York, NY, USA, 1991.

18. Morris, A.E.J. History of Urban Form before the Industrial Revolution; Routledge: New York, NY, USA, 2013.

19. Ewing, R.; Clemente, O. Measuring Urban Design: Metrics forLlivable Places; Island Press: Washington, DC, USA, 2013.

20. Ashihara, Y. Exterior Design in Architecture; Van Nostrand Reinhold Inc.: New York, NY, USA, 1970.

21. Lynch, K.; Hack, G. Site Planning; MIT Press: Cambridge, MA, USA, 1984.

22. Shin, H.-D.; Zoh, K.-J. A study of the planning process, design idea and implementation of the Gwanghwamun plaza. J. Korean Inst. Landsc. Archit. 2013, 41, 24-41. [CrossRef]

23. Yang, B. Koreans and Square. J. Environ. Stud. 2017, 59, 24-34. 
24. Shirvani Dastgerdi, A.; De Luca, G. Joining historic cities to the global world: Feasibility or fantasy? Sustainability 2019, 11, 2662. [CrossRef]

25. Krier, R.; Rowe, C. Urban Space; Academy Editions: London, UK, 1979.

26. Trancik, R. Finding Lost Space: Theories of Urban Design; John Wiley \& Sons: Hoboken, NJ, USA, 1986.

27. Memluk, M.Z. Designing Urban Squares. In Advances in Landscape Architecture; Ozyavuz, M., Ed.; IntechOpen: London, UK, 2013.

28. Gehl, J. Cities for People; Island Press: Washington, DC, USA, 2013.

29. Jacobs, A.B. Great Streets; MIT Press: Cambridge, MA, USA, 1993.

30. Alberti, L.B. The Ten Books of Architecture, The 1755 Leoni ed.; Dover Publications: New York, NY, USA, 1986.

31. Collins, G.R.; Sitte, C.; Collins, C.C. Camillo Sitte: The Birth of Modern City Planning; Dover Publications: New York, NY, USA, 2006.

32. Handy, S.L.; Boarnet, M.G.; Ewing, R.; Killingsworth, R.E. How the built environment affects physical activity: Views from urban planning. Am. J. Prev. Med. 2002, 23, 64-73. [CrossRef]

33. Whyte, W.H. City: Rediscovering the Center; University of Pennsylvania Press: Philadelphia, PA, USA, 2012.

34. Hadelich, V. Quality by Design: The Venustas of Urban Squares. In Proceedings of the CNU20, West Palm Beach, FL, USA, 9-12 May 2012.

35. Kim, J. Comparing the Influences of the D/H Ratio, Size, and Facade Design of an Enclosed Square on Its Perceptual Qualities as a Sustainable Urban Space in South Korea. Sustainability 2017, 9, 675. [CrossRef]

36. Kim, J.; Kim, S. Finding the Optimal D/H Ratio for an Enclosed Urban Square: Testing an Urban Design Principle Using Immersive Virtual Reality Simulation Techniques. Int. J. Environ. Res. Public Health 2019, 16, 865. [CrossRef] [PubMed]

37. Tang, H. An Analysis of Contemporary Urban Public Open Space Design and Construction in China: Progresses and Problems. Ph.D. Thesis, Heriot-Watt University, Edinburgh, UK, 2004.

38. Chen, $\mathrm{C}$. Designing the danceable city: How residents in Beijing cultivate health and community ties through urban dance. J. Am. Plan. Assoc. 2018, 84, 237-249. [CrossRef]

39. Nisbett, R. The Geography of Thought: How Asians and Westerners Think Differently and Why; Simon and Schuster: New York, NY, USA, 2004.

40. Heath, T.F. Beharioral and Perceptual Aspects of the Aesthetics of Urban Environments. In Environmental Aesthetics: Theory, Research, and Application; Nasar, J.L., Ed.; Cambridge University Press: New York, NY, USA, 1992; pp. 6-10.

41. Saulton, A.; Bülthoff, H.H.; De La Rosa, S.; Dodds, T.J. Cultural differences in room size perception. PLoS ONE 2017, 12, e0176115. [CrossRef]

42. Tips, W. Landscape preference evaluation and Sociocultural background-A comparison among Asian countries. J. Environ. Manag. 1986, 22, 113-124.

43. Yu, K. Cultural variations in landscape preference: Comparisons among Chinese sub-groups and Western design experts. Landsc. Urban Plan. 1995, 32, 107-126. [CrossRef]

44. Allison, M.T. Breaking boundaries and barriers: Future directions in cross-cultural research. Leisure Sci. 1988, 10, 247-259. [CrossRef]

45. Boeschenstein, W. Expressive urban color. J. Archit. Plan. Res. 1986, 3, 275-285.

46. De Vries, N.J.; Moscato, P. Consumer Behaviour and Marketing Fundamentals for Business Data Analytics. In Business and Consumer Analytics: New Ideas; De Vries, N.J., Moscato, P., Eds.; Springer: Cham, Switzerland, 2019; pp. 119-162.

47. Portman, M.E.; Natapov, A.; Fisher-Gewirtzman, D. To go where no man has gone before: Virtual reality in architecture, landscape architecture and environmental planning. Comput. Environ. Urban Syst. 2015, 54, 376-384. [CrossRef]

48. Katoshevski, R.; Timmermans, H. Using conjoint analysis to formulate user-centred guidelines for urban design: The example of new residential development in Israel. J. Urban Des. 2001, 6, 37-53. [CrossRef]

49. Levine, J.; Frank, L.D. Transportation and land-use preferences and residents' neighborhood choices: The sufficiency of compact development in the Atlanta region. Transportation 2007, 34, 255-274. [CrossRef]

50. Tayyaran, M.R. Impacts of Telecommuting, and Related Aspects of Intelligent Transportation Systems on Residential Location Choice; A Combined Revealed and Stated Preference Approach; Carleton University: Ottawa, ON, Canada, 2000. 
51. Brown, D.S.; Finkelstein, E.A.; Brown, D.R.; Buchner, D.M.; Johnson, F.R. Estimating older adults' preferences for walking programs via conjoint analysis. Am. J. Prev. Med. 2009, 36, 201-207. [CrossRef] [PubMed]

52. Xu, Q. Achieving User-Centered Place-Making: An Attempt to Apply Conjoint Analysis in Urban Design. Bachelor's Dissertation, University of Liverpool, Liverpool, UK, 2013.

53. Ghekiere, A.; Deforche, B.; Mertens, L.; De Bourdeaudhuij, I.; Clarys, P.; De Geus, B.; Cardon, G.; Nasar, J.; Salmon, J.; Van Cauwenberg, J. Creating cycling-friendly environments for children: Which micro-scale factors are most important? An experimental study using manipulated photographs. PLoS ONE 2015, 10, e0143302. [CrossRef] [PubMed]

54. Patterson, Z.; Darbani, J.M.; Rezaei, A.; Zacharias, J.; Yazdizadeh, A. Comparing text-only and virtual reality discrete choice experiments of neighbourhood choice. Landsc. Urban Plan. 2017, 157, 63-74. [CrossRef]

55. Birenboim, A.; Dijst, M.; Ettema, D.; De Kruijf, J.; de Leeuw, G.; Dogterom, N. The utilization of immersive virtual environments for the investigation of environmental preferences. Landsc. Urban Plan. 2019, 189, 129-138. [CrossRef]

56. Orme, B. Formulating Attributes and Levels in Conjoint Analysis; Sawtooth Software, Inc.: Provo, UT, USA, 2002; pp. 1-4.

57. Adamowicz, W.; Louviere, J.; Swait, J. Introduction to Attribute-Based Stated Choice Methods; National Oceanic and Atmospheric Administration: Edmonton, AB, Canada, 1998.

58. Bridges, J.F.; Hauber, A.B.; Marshall, D.; Lloyd, A.; Prosser, L.A.; Regier, D.A.; Johnson, F.R.; Mauskopf, J. Conjoint analysis applications in health-A checklist: A report of the ISPOR Good Research Practices for Conjoint Analysis Task Force. Value Health 2011, 14, 403-413. [CrossRef]

59. Wittink, D.R.; Huber, J.; Zandan, P.; Johnson, R.M. The Number of Levels Effect in Conjoint: Where Does It Come From, and Can It Be Eliminated; Sawtooth Software, Inc.: Provo, UT, USA, 1992; pp. 1-11.

60. Ikemoto, H.; Yamaoka, T. Conjoint Analysis Method That Minimizes the Number of Profile Cards. In Proceedings of the International Conference on Human-Computer Interaction, Orlando, FL, USA, 9-14 July 2011; pp. 23-28.

61. Schneider, S.; Bengler, K. Virtually the same? Analysing pedestrian behaviour by means of virtual reality. Transp. Res. Part F Traffic Psychol. Behav. 2020, 68, 231-256. [CrossRef]

62. McCullough, D. A user's guide to conjoint analysis. Mark. Res. 2002, 14, 18-23.

63. Grillon, C.; Baas, J.M.; Cornwell, B.; Johnson, L. Context conditioning and behavioral avoidance in a virtual reality environment: Effect of predictability. Biol. Psychiatry 2006, 60, 752-759. [CrossRef]

64. Saiano, M.; Pellegrino, L.; Casadio, M.; Summa, S.; Garbarino, E.; Rossi, V.; Dall'Agata, D.; Sanguineti, V. Natural interfaces and virtual environments for the acquisition of street crossing and path following skills in adults with Autism Spectrum Disorders: A feasibility study. J. Neuroeng. Rehabil. 2015, 12, 1-13. [CrossRef] [PubMed]

65. Shi, Y.; Du, J.; Ragan, E.; Choi, K.; Ma, S. Social Influence on Construction Safety Behaviors: A Multi-User Virtual Reality Experiment. In Proceedings of the Construction Research Congress, New Orleans, LA, USA, 2-4 April 2018; pp. 147-183.

66. Velasco, J.P.N.; Farah, H.; van Arem, B.; Hagenzieker, M.P. Studying pedestrians' crossing behavior when interacting with automated vehicles using virtual reality. Transp. Res. Part F Traffic Psychol. Behav. 2019, 66, 1-14. [CrossRef]

67. Gehl, J. Life Between Buildings: Using Public Space; Island Press: Washington, DC, USA, 2011.

68. Tabrizian, P.; Baran, P.K.; Smith, W.R.; Meentemeyer, R.K. Exploring perceived restoration potential of urban green enclosure through immersive virtual environments. J. Environ. Psychol. 2018, 55, 99-109. [CrossRef]

69. Gifford, R.; Hine, D.W.; Muller-Clemm, W.; Reynolds, D.A.J., Jr.; Shaw, K.T. Decoding modern architecture: A lens model approach for understanding the aesthetic differences of architects and laypersons. Environ. Behav. 2000, 32, 163-187. [CrossRef]

70. Gifford, R.; Hine, D.W.; Muller-Clemm, W.; Shaw, K.T. Why architects and laypersons judge buildings differently: Cognitive properties and physical bases. J. Archit. Plan. Res. 2002, 19, 131-148.

71. Geslin, E.; Bouchard, S.; Richir, S. Gamers' versus non-gamers' emotional response in virtual reality. J. CyberTher. Rehabil. 2011, 4, 489-493.

72. Kuliga, S.F.; Thrash, T.; Dalton, R.C.; Hölscher, C. Virtual reality as an empirical research tool—Exploring user experience in a real building and a corresponding virtual model. Comput. Environ. Urban Syst. 2015, 54, 363-375. [CrossRef] 
73. Rosling, H.; Rosling, O.; Rönnlund, A.R. Factfulness: Ten Reasons We're Wrong About The World-And Why Things Are Better Than You Think; Flatiron Books: New York, NY, USA, 2018.

74. Dwyer, J.F.; Hutchison, R. Outdoor Recreation Participation and Preferences by Black and White Chicago Households. In Social Science and Natural Resource Recreation Management; Vining, J., Ed.; Westview Press: New York, NY, USA, 1990; pp. 49-67.

75. Yang, B.-E.; Brown, T.J. A cross-cultural comparison of preferences for landscape styles and landscape elements. Environ. Behav. 1992, 24, 471-507. [CrossRef]

76. Chrzan, K.; Orme, B. An Overview and Comparison of Design Strategies for Choice-Based Conjoint Analysis. In Proceedings of the Sawtooth Software Research Paper Series, Hilton Head, SC, USA, 21-24 March 2000.

77. Getting Started: What is CBC Analysis? Available online: https://sawtoothsoftware.com/help/lighthousestudio/manual/index.html?hid_web_whatcbc.html (accessed on 22 October 2019).

(C) 2020 by the authors. Licensee MDPI, Basel, Switzerland. This article is an open access article distributed under the terms and conditions of the Creative Commons Attribution (CC BY) license (http://creativecommons.org/licenses/by/4.0/). 